\title{
Effect of body mass index on clinical outcome and all-cause mortality in patients undergoing transcatheter aortic valve implantation
}

\author{
M. Abawi ${ }^{1}$ R. Rozemeijer ${ }^{1}$ P. Agostoni ${ }^{1,2}$ - R. C. van Jaarsveld ${ }^{1}$ C. S. van Dongen ${ }^{1} \cdot$ M. Voskuil $^{1}$ $^{\prime}$ \\ A. O. Kraaijeveld ${ }^{1}$ P. A. F. M. Doevendans ${ }^{1}$ - P. R. Stella ${ }^{1}$
}

Published online: 23 May 2017

(C) The Author(s) 2017. This article is an open access publication.

\begin{abstract}
Objectives To assess the effect of body mass index (BMI) on outcome among patients with severe aortic stenosis (AS) admitted for transcatheter aortic valve implantation (TAVI). Background Being overweight or obese is associated with improved outcome following certain medical treatments, suggesting the existence of a BMI paradox. However, the relationship between BMI and mortality after TAVI remains controversial.

Methods Patients were classified according to World Health Organisation criteria such as normal weight, overweight, or obesity according to their BMI (18.5 to $24.9 \mathrm{~kg} / \mathrm{m}^{2}, 25.0$ to $29.9 \mathrm{~kg} / \mathrm{m}^{2}$, and $\geq 30.0 \mathrm{~kg} / \mathrm{m}^{2}$, respectively).

Results A total of 549 consecutive patients (age: $80.2 \pm$ 7.5 years; logistic European system for cardiac operative risk evaluation [EuroSCORE]: $17.3 \pm 9.9 \%$ ) who underwent TAVI for AS were included. Of these patients, $43 \%$ $(n=237)$ had normal weight, $36 \%(n=200)$ were overweight, and $20 \%(n=112)$ were obese. There were no differences in peri-operative bleeding or vascular complication rates between the groups. All-cause mortality after 30 days, and 1 year, were higher in normal weight patients compared with overweight and obese patients (7\% vs. 5 and $4 \%, p=0.383$, and $19 \%$ vs. 9 and $10 \%, p=0.006$, respectively). After adjustment for several confounding factors, overweight was associated with a decreased 30-day and 1-year all-cause mortality outcome (hazard ratio [HR]
\end{abstract}

P. R. Stella

p.stella@umcutrecht.nl

1 Department of Cardiology, University Medical Center Utrecht, Utrecht, The Netherlands

2 Department of Cardiology, St. Antonius Hospital, Nieuwegein, The Netherlands
0.69; 95\% confidence interval [CI] 0.47-0.99, and HR 0.65; 95\% CI 0.45-0.94, respectively).

Conclusions Despite the well-documented adverse effects of increased body weight on health, being overweight is associated with improved survival following TAVI when compared with normal weight.

Keywords Transcatheter aortic valve implantation . TAVR · Body mass index · Obesity · Overweight · Obesity paradox

\section{Introduction}

Overweight and obesity are the fifth leading modifiable cause of death in the world, accounting nearly 3.4 million deaths annually [1]. The prevalence of obesity, often defined as body mass index (BMI), has been increasing dramatically [1]. According to available data, more than twothirds of adults in the United States, and more than 2.1 billion people worldwide, suffer from obesity [1, 2]. Although it has been suggested that obesity occurs because of an energy imbalance between caloric intake and expenditure, the resulting energy excess and associated weight gain reflects a complex interaction between genes, epigenetic markers, environment, and lifestyle [2-4].

According to the Framingham Heart study, conducted among participants (age: 30-49 years) with no cardiovascular disease at baseline, overweight and obesity were associated with a decrease in life expectancy and increased early mortality during the follow-up period of $\geq 4$ years [5]. Accordingly, another population-based cohort reported an increased risk of all-cause mortality among elderly ( $\geq 85$ years) obese participants [6]. In addition to the risk of mortality, obesity is an underlying promotor of systemic 


\title{
Advertisement placed here.
}

\author{
SCS bohn \\ stafleu \\ CL van loghum \\ Springer Media
}

Houten 2017 


\title{
Advertisement placed here.
}

\author{
SCS bohn \\ stafleu \\ CL van loghum \\ Springer Media
}

Houten 2017 


\title{
Advertisement placed here.
}

\author{
SCS bohn \\ stafleu \\ CL van loghum \\ Springer Media
}

Houten 2017 


\title{
Advertisement placed here.
}

\author{
SCS bohn \\ stafleu \\ CL van loghum \\ Springer Media
}

Houten 2017 
metabolic dysfunction, i. e., dyslipidaemia, decreased insulin sensitivity, hyperinsulinaemia, hyperglycaemia, and hypertension [2, 4].

However, despite the well-documented adverse effects of overweight or obesity on general health status, being overweight or obese is associated with better survival in patients undergoing medical interventions [7], vascular surgery [8], cardiovascular intervention [9], and in patients who are hospitalised for acute decompensated heart failure [10, 11]. These observations led to the concept of reverse epidemiology, also known as the obesity paradox. The obesity paradox states that a higher BMI may, counter-intuitively, be linked to improved survival in certain patient groups. However, these observations do not support common practice where weight loss is recommended prior to cardiac treatments.

Contradicting data exist regarding the effect of BMI on outcome in patients with aortic stenosis (AS). In one study ( $n=1664$ ) overweight and obese patients with AS were at increased risk for mortality, whereas another study $(n=400)$ found contradictory results $[12,13]$. Although there are few data regarding the effect of BMI on outcome among patients with AS who undergo transcatheter aortic valve implantation (TAVI), several cohort studies showed contradicting or supporting results [14-20]. For instance, a large French Aortic National CoreValve and Edwards (FRANCE-2) registry showed improved survival outcome among overweight and obese individuals undergoing TAVI [14]. Overweight or obesity was associated with improved survival following TAVI in other cohort studies as well [21]. However, a recent study did not find such a paradoxical relationship [19]. Therefore, the current study aimed to assess the effects of body mass index on short and long-term all-cause mortality in patients undergoing TAVI in the current era.

\section{Methods}

We performed a retrospective observational cohort study encompassing all eligible consecutive patients who underwent TAVI between September 2008 and October 2016 at the University Medical Center Utrecht, Utrecht, the Netherlands. All demographic and peri-procedural data were prospectively collected in our dedicated database and retrospectively analysed in this study. All patients gave informed consent for the procedure and due to the retrospective nature of the study design, ethics committee approval was waived.

\section{Body mass index}

BMI was defined as the weight in kilograms divided by the square of the height in meters. The weight and height of all patients were prospectively collected at hospital admission before the TAVI procedure. Baseline and clinical data were stratified by BMI categories according to the World Health Organisation (WHO) criteria as normal weight, overweight, and obese (18.5 to $24.9 \mathrm{~kg} / \mathrm{m}^{2}, 25.0$ to $29.9 \mathrm{~kg} / \mathrm{m}^{2}$, and $\geq 30.0$, respectively).

\section{TAVI procedure}

All patients had been judged inoperable or at high operative risk by the Heart Team and required consensus of at least one interventional cardiologist and one cardiac surgeon. Motivations to refuse surgical aortic valve replacement (SAVR) in patients were: 1) logistic European system for cardiac operative risk evaluation [EuroSCORE] $\geq 15 \%$, or 2) the presence of contra-indications to cardiac surgery, e. g. porcelain aorta, frailty or patent grafts in proximity of the sternum. Frailty was subjectively measured prior to allocating TAVI by an interventional cardiologist and/or cardiothoracic surgeon based on the informal 'eyeball test' (including cognition function, physical weakness and walk speed). Access site was evaluated based on the measurements of pre-procedural multislice computed tomography scan. Valve implantation was performed either via the transfemoral or non-transfemoral approach (transapical or direct aortic). General anaesthesia or conscious sedation was used according to current local practice.

\section{Study endpoints}

Main endpoint of this study was all-cause mortality at 30 days and 1 year after TAVI. All clinical outcomes were documented during the hospital stay, in compliance with the Valve Academic Research Consortorium-2 (VARC-2) criteria and compared across all 3 BMI categories [22]. Vascular complications were documented for all procedural 'access sites', defined as any location traversed by a guide-wire, a catheter or a sheath during the procedure, including arteries, veins, left ventricular apex and the aorta. For the evaluation of postoperative delirium (POD) by the nurse or attending physician, a Delirium Observational Screening (DOS) scale score was rated at the end of every shift, according to the local protocol [23].

\section{Statistical analysis}

Categorical variables were expressed as frequencies and percentages and compared with the One-way ANOVA, Chisquared test or Fisher's exact test, when appropriate. We applied Bonferroni's correction in case of multiple comparisons. Continuous variables were expressed as mean and standard deviation if normally distributed or as median [in- 
terquartile range] if skewed and compared with the Student's t-test or the Mann-Whitney $U$ test, respectively.

The association between BMI as a categorical variable and all-cause mortality was analysed using Kaplan-Meier survival estimates and the Log-Rank test. We developed a Cox regression model with selected variables with a $p$-value $<0.10$ to isolate the association of BMI with all-cause mortality. All statistical analyses were carried out using the IBM Statistical Package for Social Science for Windows, version 24.0 (IBM Corp., Armonk, New York, USA).

\section{Results}

\section{Patient characteristics}

We included a total of 562 consecutive patients who underwent TAVI for severe AS in the study. Because of the small sample size, we excluded patients $(n=13)$ with BMI $\leq$ $18.5 \mathrm{~kg} / \mathrm{m}^{2}$, leaving $549(98 \%)$ patients for the final analysis. Patient characteristics of all patients included in this study are given in Table 1 .

According to the BMI categories, 43\% $(n=237)$ had normal weight, $36 \%(n=200)$ were overweight, and $20 \%$ ( $n=112$ ) were obese. BMI distribution is graphically presented in Fig. 1. Obese patients were relatively younger than normal weight and overweight patients $(78.4 \pm 7.5 \mathrm{vs}$. $80.8 \pm 7.5$ and $80.5 \pm 7.3, p=0.004$, respectively); were more often female ( $71 \%$ vs. 52 and $52 \%, p=0.001$, respectively); obese patients had, non-surprisingly, a higher prevalence of diabetes mellitus (53\% vs. 23 and $31 \%, p \leq$ 0.001 , respectively), hypertension ( $71 \%$ vs. 54 and $60 \%$, $p=0.010$, respectively), hypercholesterolaemia ( $40 \%$ vs. 27 and $39 \%, p=0.008$, respectively). Obese patients had a higher left ventricular ejection fraction (LVEF) compared with normal weight and overweight patients $(61.3 \pm 20.2 \mathrm{vs}$. $53.1 \pm 16.6$, and $52.6 \pm 16.7 \%, p \leq 0.001$, respectively). After the procedure, normal weight was associated with mild/or more than mild periprosthetic aortic valve regurgitation (PPR). No differences were observed in procedural features between the groups.

\section{Clinical outcomes}

In-hospital outcomes are summarised in Table 2. Median follow-up time was 682 [interquartile range: 328-1270] days, and $33 \%$ ( $n=181)$ deaths occurred during the followup period, with the highest rate among normal weight patients compared with overweight and obese patients $(38.4 \%$ vs. $27.5 \%$ and $31.3 \%, p=0.049$, respectively). At 30-day follow-up, as well as 1-year follow-up, all-cause mortality rates were higher in normal weight patients compared with overweight and obese patients $(6.8 \%$ vs. $4.5 \%$, and $3.6 \%$, $p=0.386$; and $18.6 \%$ vs. $9.0 \%$, and $9.8 \%, p=0.006$, respectively). There were no differences in in-hospital bleeding or vascular complications between the groups.

Unadjusted survival is presented as a Kaplan-Meier curve in Figs. 2 and 3. Estimated survival rates varied significantly among the groups after 30 days $(p=0.047$, log-rank test) and 1 year ( $p=0.017, \log$-rank test). Patients with normal weight with BMI $18.5-24.9 \mathrm{~kg} / \mathrm{m}^{2}$ had the highest mortality risk, whereas overweight patients had the lowest mortality risk.

Univariate and multivariate analysis results of the association between BMI and 30-day and 1-year mortality are shown in Table 3. After adjustment for baseline and periprocedural covariates, i.e., age, gender, New York Heart Association class $\geq$ III, diabetes mellitus, hypertension, dyslipidaemia, left ventricular ejection fraction, calcium channel blockers, beta blockers, antiarrhythmics, diuretics, angiotensin II receptor antagonists, aspirin, lipid-lowering agents, insulin, PPR $\geq$ mild, postoperative delirium, and hospital stay, only overweight was associated with a decreased 30-day and 1-year all-cause mortality rate compared with normal weight and obesity (overweight adjusted model at 30 days: hazard ratio [HR] 0.69; 95\% confidence interval [CI] 0.47-0.99; adjusted model at 1 year: HR 0.65; 95\% CI 0.45-0.94, respectively). However, there was no association between BMI as a continuous variable and mortality.

\section{Discussion}

In the present study, we aimed to evaluate the impact of body mass index on all-cause mortality and clinical outcome in patients undergoing TAVI. After adjustment, being overweight was associated with decreased 30-day and 1-year all-cause mortality, while there was no association found between obesity and mortality outcomes following TAVI. Furthermore, there were no differences observed in postoperative bleeding or vascular complications between the BMI categories.

Considering the aging population, the global prevalence of overweight and obesity is expected to rise [12]. AS is the predominant type of valvular heart disease among elderly and associated with poor prognosis [24]. Prevalence of AS is $3 \%$, increasing with age up to $10 \%$ in adults $\geq 80$ years [25]. Currently, TAVI has emerged as a valuable option to treat severe AS in elderly patients considered to be inoperable or at high surgical risk for SAVR [26]. However, fewer data exist regarding body weight management in patients undergoing TAVI.

Interestingly, we observed decreased short-term and long-term mortality outcomes after TAVI among over- 
Table 1 Baseline characteristics stratified according to the BMI categories

\begin{tabular}{|c|c|c|c|c|c|c|c|c|}
\hline & $\begin{array}{l}\text { All patients } \\
(n=549) \\
(n(\%))\end{array}$ & $\begin{array}{l}\text { NW } \\
(n=237)\end{array}$ & $\begin{array}{l}\text { OW } \\
(n=200)\end{array}$ & $\begin{array}{l}\mathrm{O} \\
(n=112)\end{array}$ & $\begin{array}{l}p \text {-value, } \\
\text { overall }\end{array}$ & $\begin{array}{l}\text { NW vs. } \\
\text { OW }\end{array}$ & $\begin{array}{l}\text { NW vs. } \\
\mathrm{O}\end{array}$ & $\begin{array}{l}\text { OW vs. } \\
\text { O }\end{array}$ \\
\hline Age, years & $80.2 \pm 7.5$ & $80.8 \pm 7.5$ & $80.5 \pm 7.3$ & $78.4 \pm 7.5$ & 0.004 & 1.000 & 0.003 & 0.025 \\
\hline Gender, male & $241(44)$ & $113(48)$ & $96(48)$ & $32(29)$ & 0.001 & 1.000 & 0.002 & 0.003 \\
\hline BMI, $\mathrm{kg} / \mathrm{m}^{2}$ & $26.6 \pm 4.4$ & $22.8 \pm 1.5$ & $27.2 \pm 1.4$ & $33.3 \pm 2.8$ & 0.000 & 0.000 & 0.000 & 0.000 \\
\hline Logistic EuroSCORE & $17.3 \pm 9.9$ & $18.1 \pm 10.6$ & $16.5 \pm 8.5$ & $17.4 \pm 10.5$ & 0.417 & 0.637 & 1.000 & 1.000 \\
\hline Frailty & $184(34)$ & $80(34)$ & $60(30)$ & $44(39)$ & 0.248 & 1.000 & 0.922 & 0.289 \\
\hline NYHA class $\geq$ III & $305(58)$ & $131(58)$ & $100(52)$ & $74(67)$ & 0.041 & 0.740 & 0.313 & 0.035 \\
\hline Estimated GFR, $\mathrm{ml} / \mathrm{min}$ & $56.3 \pm 22.5$ & $56.4 \pm 23.5$ & $57.6 \pm 20.3$ & $53.8 \pm 24.5$ & 0.460 & 1.000 & 0.867 & 0.702 \\
\hline Porcelain aorta & $58(11)$ & $25(11)$ & $24(12)$ & $9(8)$ & 0.551 & 1.000 & 1.000 & 0.828 \\
\hline Diabetes mellitus & $175(32)$ & $54(23)$ & $62(31)$ & $59(53)$ & 0.000 & 0.180 & 0.000 & 0.000 \\
\hline Hypertension & $329(60)$ & $129(54)$ & $120(60)$ & $80(71)$ & 0.010 & 0.703 & 0.007 & 0.142 \\
\hline Dyslipidemia & $185(34)$ & $63(27)$ & $77(39)$ & $45(40)$ & 0.008 & 0.025 & 0.036 & 1.000 \\
\hline Smoking (current/prior) & $178(32)$ & $81(34)$ & $67(34)$ & $30(27)$ & 0.356 & 1.000 & 0.508 & 0.675 \\
\hline Coronary artery disease & $261(48)$ & $114(48)$ & $90(45)$ & $57(51)$ & 0.591 & 1.000 & 1.000 & 0.956 \\
\hline $\begin{array}{l}\text { Prior myocardial infarc- } \\
\text { tion }\end{array}$ & $103(19)$ & $42(18)$ & $37(19)$ & $24(21)$ & 0.705 & 1.000 & 1.000 & 1.000 \\
\hline Prior PCI & $200(36)$ & $93(39)$ & $71(36)$ & $36(32)$ & 0.412 & 1.000 & 0.598 & 1.000 \\
\hline Prior CABG & $90(16)$ & $33(14)$ & $36(18)$ & $21(19)$ & 0.390 & 0.758 & 0.770 & 1.000 \\
\hline Peripheral artery disease & $118(22)$ & $59(25)$ & $36(18)$ & $23(21)$ & 0.209 & 0.243 & 1.000 & 1.000 \\
\hline Atrial fibrillation & $174(32)$ & $78(33)$ & $58(29)$ & $38(34)$ & 0.580 & 1.000 & 1.000 & 1.000 \\
\hline Active malignancy & $60(11)$ & $27(11)$ & $25(13)$ & $8(7)$ & 0.331 & 1.000 & 0.707 & 0.440 \\
\hline COPD & $109(20)$ & $50(21)$ & $37(19)$ & $22(20)$ & 0.793 & 1.000 & 1.000 & 1.000 \\
\hline Pulmonary hypertension & $38(7)$ & $16(7)$ & $12(6)$ & $10(9)$ & 0.620 & 1.000 & 1.000 & 1.000 \\
\hline Prior TIA or stroke & $108(20)$ & $47(20)$ & $41(21)$ & $20(18)$ & 0.850 & 1.000 & 1.000 & 1.000 \\
\hline \multicolumn{9}{|l|}{ Medication use } \\
\hline $\mathrm{CCBs}$ & $120(22)$ & $56(24)$ & $40(20)$ & $24(21)$ & 0.653 & 1.000 & 1.000 & 1.000 \\
\hline Beta blockers & $305(56)$ & $128(54)$ & $107(54)$ & $70(63)$ & 0.252 & 1.000 & 0.410 & 0.377 \\
\hline Antiarrhythmics & $40(7)$ & $16(7)$ & $12(6)$ & $12(11)$ & 0.281 & 1.000 & 0.553 & 0.375 \\
\hline Diuretics & $345(63)$ & $137(58)$ & $128(64)$ & $80(71)$ & 0.044 & 0.543 & 0.042 & 0.576 \\
\hline ARBs & $99(18)$ & $36(15)$ & $31(16)$ & $32(29)$ & 0.005 & 1.000 & 0.007 & 0.012 \\
\hline Aspirin & $298(54)$ & $135(57)$ & $102(51)$ & $61(55)$ & 0.459 & 0.641 & 1.000 & 1.000 \\
\hline Lipid-lowering agents & $310(57)$ & $121(51)$ & $116(58)$ & $73(65)$ & 0.039 & 0.432 & 0.039 & 0.657 \\
\hline Insulin & $70(13)$ & $16(7)$ & $29(15)$ & $25(22)$ & 0.000 & 0.044 & 0.000 & 0.134 \\
\hline \multicolumn{9}{|l|}{ Echocardiography data } \\
\hline LVEF & $54.6 \pm 17.8$ & $53.1 \pm 16.6$ & $52.6 \pm 16.7$ & $61.3 \pm 20.2$ & 0.000 & 1.000 & 0.001 & 0.000 \\
\hline $\mathrm{LVEF} \leq 30$ & $46(9)$ & $19(9)$ & $22(12)$ & $5(5)$ & 0.171 & 0.948 & 0.838 & 0.188 \\
\hline $\begin{array}{l}\text { Peak aortic gradient, } \\
\mathrm{mm} \mathrm{Hg}\end{array}$ & $66.0 \pm 23.3$ & $66.3 \pm 24.0$ & $65.3 \pm 23.5$ & $66.4 \pm 21.5$ & 0.742 & 1.000 & 1.000 & 1.000 \\
\hline $\begin{array}{l}\text { Mean aortic gradient, } \\
\mathrm{mm} \mathrm{Hg}\end{array}$ & $40.0 \pm 17.1$ & $40.3 \pm 17.6$ & $39.8 \pm 16.5$ & $39.7 \pm 16.5$ & 0.962 & 1.000 & 1.000 & 1.000 \\
\hline \multicolumn{9}{|l|}{ Procedural } \\
\hline General anaesthesia & $154(28)$ & $72(30)$ & $53(27)$ & $29(26)$ & 0.567 & 1.000 & 1.000 & 1.000 \\
\hline Non-transfemoral ${ }^{\mathrm{a}}$ & $91(17)$ & $46(19)$ & $32(16)$ & $13(12)$ & 0.181 & 1.000 & 0.230 & 0.951 \\
\hline PPR,$\geq$ mild & $32(6)$ & $21(9)$ & $6(3)$ & $5(5)$ & 0.025 & 0.025 & 0.310 & 1.000 \\
\hline
\end{tabular}

$N W$ normal weight $(18.5 \leq \mathrm{BMI} \leq 24.9), O W$ overweight $(25.0 \leq \mathrm{BMI} \leq 29.9), O$ obese (BMI $\geq 30.0), B M I$ body mass index, $G F R$ glomerular filtration rate, $P C I$ percutaneous coronary intervention, $C A B G$ coronary artery bypass grafting, $C O P D$ chronic obstructive pulmonary disease, TIA transient ischaemic attack, $C C B s$ calcium channel blockers, $A R B$ 's angiotensin II receptor blockers, $L V E F$ left ventricular ejection fraction, $P P R$ peri-prosthetic aortic valve regurgitation

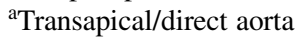




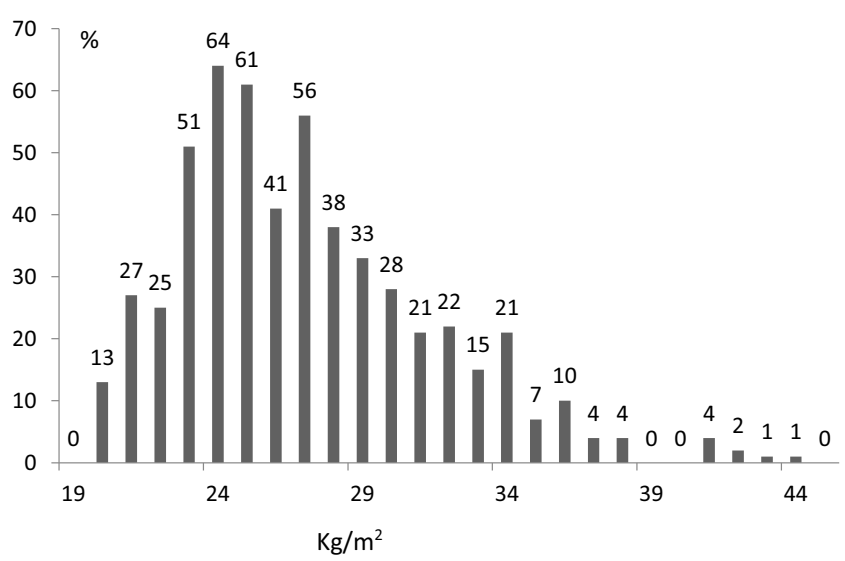

Fig. 1 Distribution of body mass index

weight patients. According to our knowledge, this is the first time such a short-term effect of overweight on mortality outcomes after TAVI has been shown. Our findings are in line with literature findings including patients who were admitted for first-time coronary artery bypass (CABG) or combined $\mathrm{CABG}$ /aortic valve replacement surgery, patients after coronary angiography for diagnosis of acute coronary syndrome, and among patients undergoing cardiac surgery [27-29]. While some studies reported no effect of being overweight on mortality outcome after TAVI [15, 19], others reported long-term positive effect of overweight on mortality outcome after TAVI [14, 17, 18]. Although current guidelines are advising weight loss and prevention of overweight and obesity, these counter-intuitive findings regarding the positive association between overweight/ obesity and mortality may create the impression that an intentional weight loss may not always be favourable.

Generally, obesity has been associated with adverse clinical health status [4], however, we observed no association between obesity and mortality after TAVI. Our results are in line with some previous reports [15, 18, 19], however, several other studies including a meta-analysis, found a beneficial effect of obesity on mortality outcome after TAVI [14, $17,21]$. In addition, inconstancies in these contradictive observations could be explained by unhealthy metabolic profile (i. e., hypertension, dyslipidaemia, diabetes) of obese individuals included in our study that may have influenced the results [30].

Although we observed no association between BMI as a continuous variable and mortality, several other studies reported a gradual reduction in death rate for every increment in BMI unit $\left(\mathrm{kg} / \mathrm{m}^{2}\right)$ during short-term or long-term followup after TAVI [15-17]. However, a recent study among patients $(n=4571)$ undergoing TAVI demonstrated that an increase in BMI was associated with higher risk of mortality in patients with elevated BMI $\left(>32 \mathrm{~kg} / \mathrm{m}^{2}\right)$ [20]. Moreover, a ' $U$ ' shape association between BMI a continuous variable and mortality was found among patients with diabetes, acute heart failure and in patients undergoing cardiac surgery $[29,31,32]$.

While performing TAVI in overweight or obese individuals may be challenging due to vascular access site and

Table 2 Clinical outcomes

\begin{tabular}{|c|c|c|c|c|c|c|c|c|}
\hline & $\begin{array}{l}\text { All patients } \\
(n(\%))\end{array}$ & NW & OW & $\mathrm{O}$ & $\begin{array}{l}p \text {-value, } \\
\text { overall }\end{array}$ & $\begin{array}{l}\text { NW vs. } \\
\text { OW }\end{array}$ & $\begin{array}{l}\mathrm{NW} \text { vs. } \\
\mathrm{O}\end{array}$ & $\begin{array}{l}\text { OW vs. } \\
\text { O }\end{array}$ \\
\hline \multicolumn{9}{|c|}{ Bleeding complications } \\
\hline $\begin{array}{l}\text { Life-threatening or } \\
\text { major }\end{array}$ & $78(14)$ & $35(15)$ & $27(14)$ & $16(14)$ & 0.931 & 1.000 & 1.000 & 1.000 \\
\hline Minor & $82(15)$ & $31(13)$ & $35(18)$ & $16(14)$ & 0.424 & 0.593 & 1.000 & 1.000 \\
\hline \multicolumn{9}{|c|}{ Vascular complications } \\
\hline Major & $76(14)$ & $33(14)$ & $27(14)$ & $16(14)$ & 0.980 & 1.000 & 1.000 & 1.000 \\
\hline Minor & $74(14)$ & $29(12)$ & $30(15)$ & $15(13)$ & 0.701 & 1.000 & 1.000 & 1.000 \\
\hline AKI stage $\geq 2$ & $29(5)$ & $18(8)$ & $7(4)$ & $4(4)$ & 0.108 & 0.170 & 0.350 & 1.000 \\
\hline PPI & $54(10)$ & $24(10)$ & $15(8)$ & $15(13)$ & 0.246 & 1.000 & 1.000 & 0.292 \\
\hline New onset $\mathrm{AF}$ & $72(13)$ & $34(14)$ & $27(14)$ & $11(10)$ & 0.495 & 1.000 & 0.731 & 1.000 \\
\hline TIA or stroke & $22(4)$ & $8(3)$ & $8(4)$ & $6(5)$ & 0.392 & 1.000 & 1.000 & 1.000 \\
\hline POD & 77 (14) & 45 (19) & $19(10)$ & $13(12)$ & 0.012 & 0.013 & 0.189 & 1.000 \\
\hline Infection $^{a}$ & $38(7)$ & $19(8)$ & $13(7)$ & $6(5)$ & 0.631 & 1.000 & 1.000 & 1.000 \\
\hline $\begin{array}{l}\text { In-hospital stay, } \\
\text { days }\end{array}$ & $6.7 \pm 5.4$ & $7.3 \pm 6.3$ & $6.1 \pm 20$ & $6.7 \pm 5.8$ & 0.057 & 0.050 & 1.000 & 0.864 \\
\hline $\begin{array}{l}\text { In-hospital mortal- } \\
\text { ity }\end{array}$ & $22(4)$ & $12(5)$ & $6(3)$ & $4(4)$ & 0.395 & 0.823 & 1.000 & 1.000 \\
\hline
\end{tabular}

$N W$ normal weight $(18.5 \leq \mathrm{BMI} \leq 24.9), O W$ overweight $(25.0 \leq \mathrm{BMI} \leq 29.9), O$ obese $(\mathrm{BMI} \geq 30.0), A K I$ acute kidney injury, $P P I$ permanent pacemaker implantation, $A F$ atrial fibrillation, TIA transient ischaemic attack, $P O D$ postoperative delirium

anfections (Urinary tract, OR access site, OR pneumonia, OR combined). 


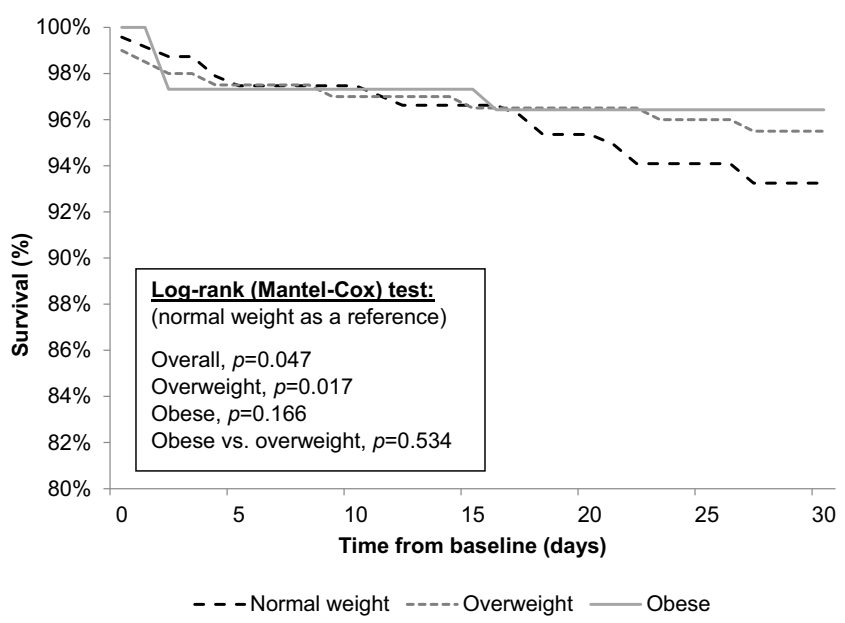

Fig. 2 Thirty-day all-cause mortality, graphically presented by Kaplan-Meier survival curves

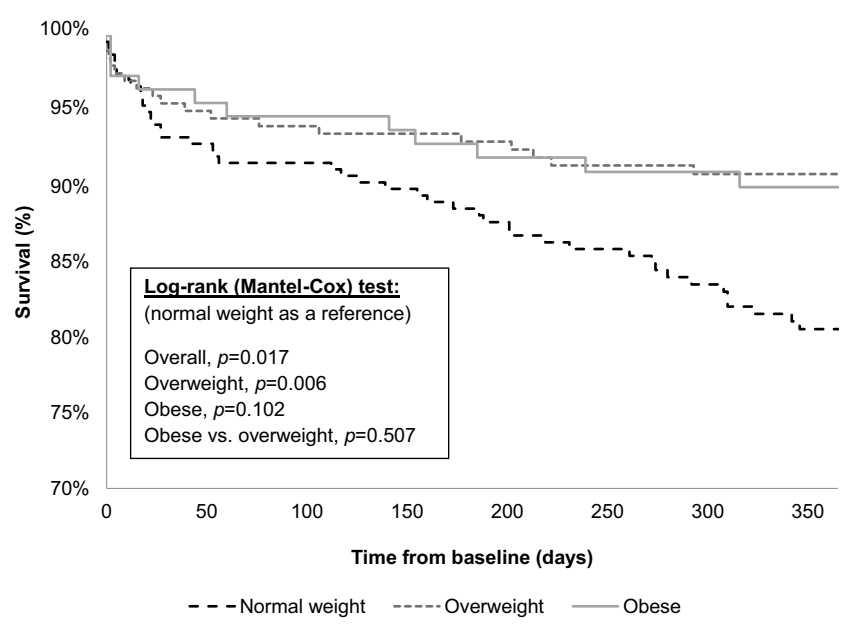

Fig. 3 One-year all-cause mortality, graphically presented by Kaplan-Meier survival curves

fluoroscopic visualisation [33], there were no differences in vascular and bleeding complications observed between the BMI groups in our cohort. These findings are in line with a recent meta-analysis evaluating the effect of BMI on outcome after TAVI [21]. This could be explained by improved TAVI technique and sustained efficacy of TAVI. However, previous studies using early-generation transcatheter aortic valves and techniques reported higher postoperative complication rates among overweight/obese and underweight individuals after TAVI. For instance, in a multi-centre study $(n=940)$, higher rates of postoperative minor stroke, minor vascular complications and acute kidney injury stage 1 were observed among obese individuals following TAVI [15]. Consistent with these findings, another study $(n=409)$ reported higher incidence of major postoperative vascular complications and a trend toward more major and life-threatening bleeding events among obese patients after TAVI [17]. Furthermore, a higher rate of major vascular complications was observed in patients with underweight. However, according to another study, BMI $<20$ compared with BMI $>20$ was not associated with adverse events following TAVI [34]. Inconsistencies in reported results could be explained by different definitions of BMI, i.e., BMI either as a categorical or continuous variable, which could lead to uncertainty in defining the cut-off points and interpretation of results. Therefore, studies should report their results according to the standardised BMI classification, i. e., WHO classification.

The mechanism behind the obesity paradox remains unclarified [35]. However, there are several possible factors that could explain the paradoxical effect of BMI on clinical outcomes. For instance, excess body weight may increase metabolic reserve and counteract the negative effects of acute injuries. Furthermore, patients with ischaemic heart failure appear to have a higher level of TNF-a concentrations compared with those with a non-ischaemic aetiology [36]. Moreover, adipose tissue has been shown to produce TNF-a receptors [37], therefore, overweight and obese patients may have a protective buffer from the negative effect of increasing TNF-a by producing higher levels of these receptors. Furthermore, several other investigators argue that the obese group, consisting of younger individuals, seeks medical care earlier, is treated medically more aggressively, and therefore benefits more from medical and interventional treatments [38]. However, these differences did not affect the outcome after adjustments in the multivariate model, even though obese individuals in our cohort were younger and used more baseline medications, i. e., diuretics, angiotensin II receptor antagonists, lipid-lowering agents, or insulin, compared with the normal weight group.

BMI either as a continuous or categorical variable has been frequently used to define body weight. However, BMI does not discriminate between the component of body fat, the type and location of fat in the body, or the degree of metabolic diseases that it can cause. In the clinical setting, high muscle mass/low fat has been associated with improved survival in patients with cardiovascular disease [39]. Accordingly, loss of muscle mass has been associated with increased mortality in patients undergoing TAVI [40]. That is why future studies are necessary to determine the most favourable body weight to improve outcome after TAVI.

This study has several important limitations. First, this retrospective, single-centre analysis is subjected to the limitations common to this type of analysis. An observational analysis, including the current study, cannot prove or disprove the existence of a paradoxical relationship between BMI and mortality. Second, we used BMI as a surrogate of body weight. However, combining BMI and measures of central obesity, such as waist circumference and waist-tohip ratio, may be more valuable in the assessment of mortal- 
Table 3 Effect of body weight on all-cause mortality during follow-up

\begin{tabular}{|c|c|c|c|c|}
\hline & $\begin{array}{l}\text { Univariate } \\
\mathrm{HR}(95 \% \mathrm{CI})\end{array}$ & $p$ & $\begin{array}{l}\text { Multivariate }^{\mathrm{a}} \\
\text { HR }(95 \% \text { CI) }\end{array}$ & $p$ \\
\hline \multicolumn{5}{|l|}{ At 30-day follow-up } \\
\hline Body mass index ${ }^{\mathrm{b}}$ & $0.98(0.95-1.01)$ & 0.258 & $0.98(0.94-1.02)$ & 0.374 \\
\hline Normal weight vs. overweight & $0.70(0.50-0.98)$ & 0.038 & $0.68(0.45-0.95)$ & 0.027 \\
\hline Normal weight vs. obese & $0.79(0.54-1.17)$ & 0.237 & $0.81(0.50-1.29)$ & 0.370 \\
\hline Overweight vs. obese & $1.13(0.74-1.72)$ & 0.583 & $1.18(0.71-1.96)$ & 0.520 \\
\hline \multicolumn{5}{|l|}{ At 1-year follow-up } \\
\hline Body mass index ${ }^{\mathrm{b}}$ & $0.98(0.94-1.01)$ & 0.189 & $0.97(0.94-1.02)$ & 0.217 \\
\hline Normal weight vs. overweight & $0.65(0.47-0.91)$ & 0.013 & $0.69(0.43-0.88)$ & 0.009 \\
\hline Normal weight vs. obese & $0.74(0.50-1.10)$ & 0.136 & $0.70(0.43-1.12)$ & 0.133 \\
\hline Overweight vs. obese & $1.14(0.75-1.74)$ & 0.547 & $1.19(0.72-1.96)$ & 0.497 \\
\hline
\end{tabular}

$H R$ hazard ratio, $C I$ confidence interval

aAdjusted for: age, gender, New York Heart Association (NYHA) class $\geq$ III, diabetes mellitus, hypertension, dyslipidaemia, left ventricular ejection fraction (LVEF), calcium channel blockers, beta blockers, antiarrhythmics, diuretics, angiotensin II receptor blockers, aspirin, lipid-lowering agents, insulin, periprosthetic aortic valve regurgitation (PPR) $\geq$ mild, postoperative delirium, hospital stay

${ }^{\mathrm{b}}$ As a continuous variable

ity risk after TAVI, since central obesity predicts mortality more reliably than BMI alone in patients with coronary heart disease [41]. Third, in contrast to other findings, only overweight was associated with decreased mortality in patients in our cohort. However, it is possible that patients with a more severe profile of comorbidities and a high surgical risk for TAVI were refused to undergo TAVI, which could have affected current results. Fourth, we may not have included all possible (unknown) confounding factors that may have influenced the results. For instance, to address the likely bias attributed to patients with cachexia, we excluded patients with BMI $<18.5$. However, as most elderly suffer from lower muscle mass, this will introduce bias attributable to unassured confounders [40]. Fifth, we could not address the effect of BMI changes over time, which may have influenced our results. Finally, although late mortality after TAVI may be attributed to the non-cardiac causes [42], we could not address the cause of death in patients included in this study. Future studies are needed to evaluate cause of death to provide a better understanding of the mechanism of the observed association between BMI and mortality.

\section{Conclusions}

Being overweight is associated with improved survival after TAVI. Furthermore, TAVI is safe in different BMI groups with respect to the postoperative complications rate.

Conflict of interest P.R. Stella is a member of the scientific advisory board Keystone Heart. M. Abawi, R. Rozemeijer, P. Agostoni, R.C. van Jaarsveld, C.S. van Dongen, M. Voskuil, A.O. Kraaijeveld and P.A.F.M. Doevendans declare that they have no competing interests.
Open Access This article is distributed under the terms of the Creative Commons Attribution 4.0 International License (http:// creativecommons.org/licenses/by/4.0/), which permits unrestricted use, distribution, and reproduction in any medium, provided you give appropriate credit to the original author(s) and the source, provide a link to the Creative Commons license, and indicate if changes were made.

\section{References}

1. Ng M, Fleming T, Robinson M, et al. Global, regional, and national prevalence of overweight and obesity in children and adults during 1980-2013: a systematic analysis for the Global Burden of Disease Study 2013. Lancet. 2014;384:766-81.

2. O'Brien PD, Hinder LM, Callaghan BC, Feldman EL. Neurological consequences of obesity. Lancet Neurol. 2017;16:465-77.

3. Raman J, Smith E, Hay P. The clinical obesity maintenance model: an integration of psychological constructs including mood, emotional regulation, disordered overeating, habitual cluster behaviours, health literacy and cognitive function. J Obes. 2013. doi: $10.1155 / 2013 / 240128$.

4. Haslam DW, James WPT. Obesity. Lancet. 2005;366:1197-209.

5. Peeters A, Barendregt JJ, Willekens F, et al. Obesity in adulthood and its consequences for life expectancy: a life-table analysis. Ann Intern Med. 2003;138:24-32.

6. Bowman K, Delgado J, Henley WE, et al. Obesity in older people with and without conditions associated with weight loss: follow-up of 955,000 primary care patients. J Gerontol A Biol Sci Med Sci. 2017;72:203-9.

7. Zheng W, McLerran DF, Rolland B, et al. Association between body-mass index and risk of death in more than 1 million Asians. N Engl J Med. 2011;364:719-29.

8. Galyfos G, Geropapas GI, Kerasidis S, et al. The effect of body mass index on major outcomes after vascular surgery. J Vasc Surg. 2017;65(4):1193. doi:10.1016/j.jvs.2016.09.032.

9. Bundhun PK, Li N, Chen MH. Does an obesity paradox really exist after cardiovascular intervention?: a systematic review and metaanalysis of randomized controlled trials and observational studies. Medicine (Baltimore). 2015;94:e1910.

10. Fonarow GC, Srikanthan P, Costanzo MR, et al. An obesity paradox in acute heart failure: analysis of body mass index and inhospital 
mortality for 108,927 patients in the Acute Decompensated Heart Failure National Registry. Am Heart J. 2007;153:74-81.

11. Shah R, Gayat E, Januzzi JL Jr., et al. Body mass index and mortality in acutely decompensated heart failure across the world: a global obesity paradox. J Am Coll Cardiol. 2014;63:778-85.

12. Rogge BP, Cramariuc D, Lonnebakken MT, et al. Effect of overweight and obesity on cardiovascular events in asymptomatic aortic stenosis: a SEAS substudy (Simvastatin Ezetimibe in Aortic Stenosis). J Am Coll Cardiol. 2013;62:1683-90.

13. Rossi A, Gaibazzi N, Bellelli G, et al. Obesity paradox in patients with aortic valve stenosis. Protective effect of body mass index independently of age, disease severity, treatment modality and noncardiac comorbidities. Int J Cardiol. 2014;176:1441-3.

14. Yamamoto M, Mouillet G, Oguri A, et al. Effect of body mass index on 30- and 365-day complication and survival rates of transcatheter aortic valve implantation (from the FRench Aortic National CoreValve and Edwards 2 [FRANCE 2] registry). Am J Cardiol. 2013;112:1932-7.

15. van der Boon RM, Chieffo A, Dumonteil N, et al. Effect of body mass index on short- and long-term outcomes after transcatheter aortic valve implantation. Am J Cardiol. 2013;111:231-6.

16. Arsalan M, Filardo G, Kim WK, et al. Prognostic value of body mass index and body surface area on clinical outcomes after transcatheter aortic valve implantation. Clin Res Cardiol. 2016;105:1042-8.

17. Konigstein M, Havakuk O, Arbel Y, et al. The obesity paradox in patients undergoing transcatheter aortic valve implantation. Clin Cardiol. 2015;38:76-81.

18. Gonzalez-Ferreiro R, Munoz-Garcia AJ, Lopez-Otero D, et al. Prognostic value of body mass index in transcatheter aortic valve implantation: a "J"-shaped curve. Int J Cardiol. 2017;232:342-7. doi:10.1016/j.ijcard.2016.12.051.

19. Abramowitz Y, Chakravarty T, Jilaihawi H, et al. Impact of body mass index on the outcomes following transcatheter aortic valve implantation. Catheter Cardiovasc Interv. 2016;88:127-34.

20. Gilard M, Schluter M, Snow TM, et al. The 2011-2012 pilot European Society of Cardiology Sentinel Registry of transcatheter Aortic Valve Implantation: 12-month clinical outcomes. EuroIntervention. 2016;12:79-87.

21. Sannino A, Schiattarella GG, Toscano E, et al. Meta-analysis of effect of body mass index on outcomes after transcatheter aortic valve implantation. Am J Cardiol. 2017;119:308-16.

22. Kappetein AP, Head SJ, Genereux P, et al. Updated standardized endpoint definitions for transcatheter aortic valve implantation: the Valve Academic Research Consortium-2 consensus document. J Thorac Cardiovasc Surg. 2013;145:6-23.

23. Schuurmans MJ, Shortridge-Baggett LM, Duursma SA. The delirium observation screening scale: a screening instrument for delirium. Res Theory Nurs Pract. 2003;17:31-50.

24. Carabello BA. Introduction to aortic stenosis. Circ Res. 2013;113: $179-85$.

25. Eveborn GW, Schirmer H, Heggelund G, et al. The evolving epidemiology of valvular aortic stenosis. the Tromso study. Heart. 2013;99:396-400.
26. Smith CR, Leon MB, Mack MJ, et al. Transcatheter versus surgical aortic-valve replacement in high-risk patients. N Engl J Med. 2011;364:2187-98.

27. Johnson AP, Parlow JL, Whitehead M, et al. Body mass index, outcomes, and mortality following cardiac surgery in Ontario, Canada. J Am Heart Assoc. 2015;4(7):e002140.

28. Angeras O, Albertsson P, Karason K, et al. Evidence for obesity paradox in patients with acute coronary syndromes: a report from the Swedish Coronary Angiography and Angioplasty Registry. Eur Heart J. 2013;34:345-53.

29. Mariscalco G, Wozniak MJ, Dawson AG, et al. Body-mass index and mortality among adults undergoing cardiac surgery: a nationwide study with a systematic review and Meta-analysis. Circulation. 2016;119:308-16.

30. Hamer M, Stamatakis E. Metabolically healthy obesity and risk of all-cause and cardiovascular disease mortality. J Clin Endocrinol Metab. 2012;97:2482-8.

31. Chang HW, Li YH, Hsieh CH, et al. Association of body mass index with all-cause mortality in patients with diabetes: a systemic review and meta-analysis. Cardiovasc Diagn Ther. 2016;6:109-19.

32. Parissis J, Farmakis D, Kadoglou N, et al. Body mass index in acute heart failure: association with clinical profile, therapeutic management and in-hospital outcome. Eur J Heart Fail. 2016;18:298-305.

33. Kische S, D'Ancona G, Agma HU, et al. Transcatheter aortic valve implantation in obese patients: overcoming technical challenges and maintaining adequate hemodynamic performance using new generation prostheses. Int J Cardiol. 2016;220:909-13.

34. Yamamoto M, Hayashida K, Watanabe Y, et al. Effect of body mass index $<20 \mathrm{~kg} / \mathrm{m}(2)$ on events in patients who underwent transcatheter aortic valve replacement. Am J Cardiol. 2015;115:227-33.

35. Goyal A, Nimmakayala KR, Zonszein J. Is there a paradox in obesity? Cardiol Rev. 2014;22:163-70.

36. Deswal A, Petersen NJ, Feldman AM, et al. Cytokines and cytokine receptors in advanced heart failure: an analysis of the cytokine database from the Vesnarinone trial (VEST). Circulation. 2001;103:2055-9.

37. Mohamed-Ali V, Goodrick S, Bulmer K, et al. Production of soluble tumor necrosis factor receptors by human subcutaneous adipose tissue in vivo. Am J Physiol. 1999;277:E971-5.

38. Chrysant SG, Chrysant GS. New insights into the true nature of the obesity paradox and the lower cardiovascular risk. J Am Soc Hypertens. 2013;7:85-94.

39. Srikanthan P, Horwich TB, Tseng $\mathrm{CH}$. Relation of muscle mass and fat mass to cardiovascular disease mortality. Am J Cardiol. 2016;117:1355-60.

40. Mok M, Allende R, Leipsic J, et al. Prognostic value of fat mass and skeletal muscle mass determined by computed tomography in patients who underwent transcatheter aortic valve implantation. Am J Cardiol. 2016;117:828-33.

41. Coutinho T, Goel K, Correa de Sa D, et al. Combining body mass index with measures of central obesity in the assessment of mortality in subjects with coronary disease: role of "normal weight central obesity". J Am Coll Cardiol. 2013;61:553-60.

42. Gilard M, Eltchaninoff H, Donzeau-Gouge P, et al. Late outcomes of transcatheter aortic valve replacement in high-risk patients: the FRANCE-2 registry. J Am Coll Cardiol. 2016;68:1637-47. 